\title{
Typology in the classroom: Fostering Motion-Event awareness in Spanish-speaking ELLs
}

\section{Tipología en el aula de clase: la adopción de la conciencia del "motion-event" en aprendices del inglés de habla española}

Reid Evans ${ }^{1}$

Citation / Para citar este artículo: Evans, R. (2015). Typology in the classroom: Fostering motion-event awareness in Spanish-speaking ELLs. Colomb. Appl. Linguist. J., 17(1), pp. 11-24,

Received: 09-Apr-2014 / Accepted: 21-Jan-2015

DOI: http://dx.doi.org/10.14483/udistrital.jour.calj.2015.1.a01

\begin{abstract}
The aim of the present paper is to address the implications of the direct instruction of the linguistic typology of verbs of motion in English second-language learners. Results of a small-scale research study are reported in which students were exposed to typology instruction with the goal of increasing proficiency and target-like production. To this end, it was hypothesized that pre- and post-intervention writing samples would differ significantly in the appropriate use of expressions of motion, particularly those expressions employing English manner-of-motion verbs. Results confirmed this hypothesis and demonstrated that students achieve greater proficiency in motion-event expression when exposed to explicit instruction including negative evidence and aspects of the Conceptual Approach (White, 2012).
\end{abstract}

Keywords: The conceptual approach, linguistic typology, negative evidence, linguistic typology, verbs of motion

\section{Resumen}

El presente artículo revisa implicaciones relacionadas con la enseñanza directa de la tipología lingüística de verbos de movimiento en el proceso de aprendizaje del inglés como lengua extranjera. Se presentan resultados de un estudio a menor escala en el cual primó la enseñanza de esta tipología de manera directa con el fin de fomentar la competencia y la producción natural de las estructuras en mención. Para tal efecto, se planteó una hipótesis argumentando que las muestras de escritura indicarían un cambio significativo en cuanto al uso de las expresiones de movimiento en inglés, sobre todo en aquellas que emplean verbos que expresan manera de movimiento. Los resultados confirmaron esta hipótesis y demostraron que los estudiantes alcanzaron una producción más natural con la enseñanza directa que incluye evidencias negativas y ciertos aspectos del Conceptual Approach (White, 2012).

Palabras clave: The Conceptual Approach, evidencias negativas, tipología lingüística, verbos de movimiento

1 Universidad El Bosque, Bogotá, Colombia. revans0214@gmail.com 


\section{Introduction}

As the expression of motion varies greatly across languages, such systematic expression often presents considerable hurdles to L2 acquisition (Aske, 1989; Brown E Chen, 2013; Evans, 2013; Filipović \& Vidaković, 2010; Gor, Cook, Malyushenkova, $\varepsilon$ Vdovina, 2009; Stam, 2006; 2010). Difficulties in this area are particularly salient when a learner's L1 and L2 differ in terms of the representative expressions of motion that characterize such languages. Languages such as English are characterized by the pervasive use of verbs expressing manner of motion, yet others such as Spanish frequently omit such manner descriptions in similar expressions (Cadierno $\mathcal{E}$ Robinson, 2009; Cadierno E Ruiz, 2006; Carrol, Murcia-Serra, \& Watorek, 2000; Filipović, 2008). In accordance with the typology of motion events as proposed by Talmy (2000), English and Spanish typically contrast in the expression of the elements of motion, path, and manner when communicating motion. The extent of such typological differences has been thoroughly explored in the literature, and has been enumerated in many world languages. Much of this research has examined both the typological classifications of languages as well as comparisons between languages and subsequent effects on L2 acquisition as well. Examples of such comparative research include English/Spanish (Kersten et al., 2010; Larrañaga, Treffers-Daller, Tidball, $\varepsilon$ Gil Ortega, 2012), English/Russian (Elliott $\varepsilon$ Yountchi, 2009; Gor, Cook, Malyushenkova, \& Vdovina, 2009; Hasko, 2009), English/Basque/Spanish (IbarretxeAntuñano, 2004, 2009, 2012), English/Chinese (Ji, Hendricks, E Hickman, 2011; Wu, 2011), English/ Serbian (Filipović \& Vidaković, 2010), Spanish/ Danish (Cadierno, 2010; Cadierno \& Ruiz, 2006), and even classifications of the Austronesian languages (Rau, Chun-Chieh, \& Hui-Huan, 2012).

The bulk of such research has investigated the cognitive development of L2 learners when confronted with novel typological structures; however, the question of whether specific pedagogical interventions can positively affect motion-event awareness still remains (Spring, 2010). Furthermore, didactic materials designed to expose L2 learners to the specific difference in motion-event expression between languages are uncommon
(Tyler \& Evans, 2004). In order to address these issues, the present study examines the acquisition of motion event awareness in Spanish-speaking English language learners (ELLs) via an innovative pedagogical implementation.

\section{The Typology of English and Spanish}

The notion of typology (Talmy, 2000) as referenced within this study requires further elaboration as it is through this conceptual model that motion-event expression is categorized across languages. When a language user wishes to express movement, he or she is restricted to the available linguistic resources which are most pervasive within that language (Gor, Cook, Malyushenkova, E Vdovina, 2009; Stam, 2006). The resulting articulation is guided by a language's specific lexicalization patterns (Talmy, 2000) and embodies the specific semantic and syntactic patterns which a particular language provides to the speaker at the moment of locution. While all languages provide sufficient resources to express all conceptualized notions, the manner in which these expressions are constructed varies across languages (Evans $\mathcal{E}$ Green, 2006). This becomes particularly evident when examining expressions of motion and the way in which languages permit the conveyance of figure, ground, path, and motion (Talmy, 2000). The following examples serve to illustrate the previous terms:

(1a) The prisoners crept under the tower.

(1b) The prisoners stood under the tower.

In (1a) and (1b), the prisoners represent the figure, or the moving object within a motion event. Such an object may be locative as in (1a), or may represent the perpetuation of a spatial position as demonstrated in (1b). According to Talmy's (2000) proposed typology, both translational (i.e. crept) and perpetuated (i.e. stood) spatial positions are considered as motion events. In both examples (1a) and (1b), the tower represents the ground, or the reference for the movement of the figure. Motion is evidenced in the previous examples via the infinitives to creep and to stand; however, these verbs in English do not inherently express the path of motion which, consequently, is communicated outside of 
the verb nucleus in what Talmy (2000) refers to as a satellite, or any particle standing apart from the verb root generally involved in expressing path. The English preposition under, as demonstrated in (1a) and (1b), exhibits the function of a satellite whose use defines the path of motion communicated in the sentence. Finally, the verb to creep in (1a) demonstrates what Talmy refers to as a manner coevent, or "an associated motion that often expresses the manner in which the event occurred" (Evans, 2013, p. 29). The motion-event expressions as seen in (1a) and (1b) are typical of satellite-framed languages (s-framed), or those languages which tend to conflate motion and manner within the verb nucleus leaving path to be expressed outside of the verb in a satellite. The s-framed lexicalization pattern is characteristic of many world languages, and English is a representative example of such a pattern.

In contrast to the s-framed pattern, Spanish is inclined to lexicalize motion in a dissimilar fashion. Characteristic of verb-framed languages (v-framed), Spanish verbs of motion tend to include both motion and path aspects, leaving manner of motion to be communicated outside of the verb nucleus, generally in an adverbial (Gor, Cook, Malyushenkova, E Vdovina, 2009). Such path verbs are used extensively in Spanish (as well as other Romance languages) and are representative of everyday speech. Common path verbs in Spanish include entrar (to enter), salir (to exit), atravesar (to cross), and meterse (to get/go into), and the use of such path verbs constitutes the majority of motionevent expression (Filipović, 2008). Examples (2a) and (2b) demonstrate the characteristic use of path verbs in Spanish:

(2a) Los niños atravesaron al río.

The children crossed the river.

(2b) Los niños atravesaron al río nadando.

${ }^{*}$ The children crossed the river swimming.

(2c) The children swam across the river.

The use of the Spanish verb atravesar in (2a) and (2b) inherently indicates movement which originated on one side of the river and terminated on the other. Manner of motion, however, is absent from $(2 \mathrm{a})$ as the path verb atravesar does not communicate such a co-event. In order for the manner co-event to be articulated in Spanish, the adverb nadando must be added as a compliment to the motion/path atravesaron. The translation of (2b), as denoted with (*), may be grammatical in English, yet would most likely be articulated as that in (2c) employing the manner-of-motion verb to swim with the path satellite across.

\section{Telicity}

The verb- and satellite-framed dichotomy becomes even more distinct when path predicates that express telicity are taken into account. A telic event is one that is said to articulate completed events (Filipovíc, 2008), or those which involve an endpoint, or some other termination (Hacohen, 2006). Telic events, particularly those which communicate a boundary crossing movement, are typically expressed in Germanic languages via a path satellite which may be attached to mannerof-motion verbs. In his seminal work, Aske (1989) discusses path predicates in English and Spanish and suggests that "Spanish manner (activity) verbs cannot lexicalize motion... because path in Spanish has to be expressed on the verb" (p. 2). In the following examples (3a) and (3b), the telic, boundary-crossing event of running into a house is demonstrated:

(3a) The dog ran into the house.

(3b) El perro entró a la casa corriendo.

(3c) *El perro corrió en la casa.

The English expression of telicity in (3a) is a clear example of an s-framed construction of motion and manner within the verb nucleus, with the collocation of the path satellite into used to communicate path. The Spanish equivalent, however, cannot communicate the same manner information directly on the verb. The example (3b) makes use of the Spanish verb entrar to express the boundarycrossing event, leaving the manner of motion to be expressed with the adverb corriendo. The example (3c), which represents a direct translation of (3a), inherently communicates contrasting information. The Spanish phrase correr en la casa can only demonstrate movement contained within the house in English (to run around inside the house) and not the boundary-crossing event as in (3b) as such telic 
constructions are simply not possible in Spanish (Aske, 1989; Larrañaga, Treffers-Daller, Tidball, \& Gil Ortega, 2012). L2 learners who are not familiar with the difference in telic expression may succumb to erroneously constructing such expressions in the manner of their L1; furthermore, speakers of v-framed languages may omit manner expression all together as this is characteristic of their L1 (Carroll, Murcia-Serra, E Watorerk, 2000).

\section{L1 and L2 Motion Event Expression}

The difference between $s$ - and $v$-framed languages has previously been demonstrated to present unique hurdles to the L2 learner. Addressing this concern, several empirical studies have investigated the cognitive development of motion event awareness of language learners whose L1 and L2 differ typologically (CifuentesFérez \& Gentner, 2006; Kersten et al., 2010; Larrañaga, Treffers-Daller, Tidball, $\varepsilon$ Gil Ortega, 2012; Naigles $\mathcal{E}$ Terrazas, 1998; Papafragou $\mathcal{E}$ Selimis, 2010; Papafragou, Massey, \& Gleitman, 2006; Skordos \& Papafragou, 2014). These studies have begun to paint the picture of motionevent awareness in L1 and L2 language users and offer important implications for L2 language pedagogy. Larrañaga, Treffers-Daller, Tidball, and Gil Ortega (2012) explored the acquisition of path and manner in native English speaking L2 learners of Spanish. The researchers hypothesized that native English speakers would struggle with the acquisition of manner in Spanish due to the low salience of such expression in colloquial discourse. Through the recording of oral narratives, motionevent lexicalizations were analyzed to determine the quantity and type of transfer present in the participants' speech. The researchers determined that learners with an s-framed L1 tend to express manner more than path, and that "the most plausible explanation for the students' choices is that they transfer the English ways to express motion to Spanish, yielding non-target-like results" (Larrañaga, Treffers-Daller, Tidball, \& Gil Ortega, 2012, p. 33). As such, it is reasonable to anticipate similar linguistic transfer difficulties with Spanishspeaking ELLs whose L1 focuses less on manner of movement and more on path.
Naigles and Terrazas (1998), Cifuentes-Férez and Gentner (2006), and Kersten et al. (2010) examined the extent to which native speakers rely on the characteristic semantic patterns of English and Spanish when confronted with novel verbs of motion. These researchers tested native speakers' responses to novel vocabulary with varying methodologies, yet their analysis of such input provided similar conclusions. Naigles and Terrazas (1998) employed video frames to demonstrate novel verbs after which participants were shown two screens representing either manner-of-motion or a path-of-motion lexicalizations. When asked to point to the screen which they believed best represented the novel word, English speakers overwhelmingly selected the manner condition and Spanish speakers the path condition, thus demonstrating that generalizations regarding meanings of novel words typically result as a consequence of the lexicalization patterns prevalent in the speaker's L1. Similar results were reported from Cifuentes-Férez and Gentner (2006) who employed written passages containing novel words to address the same issue. Participants were provided with passages containing novel words, after which they answered questions related to the story and provided information as to the understood meaning of each new word. As predicted, Spanish speakers produced more responses containing path verbs, and English speakers more manner verbs, with English speakers also providing more satellites than Spanish speakers.

Finally, Kersten et al. (2010) examined manner and path depictions in monolingual speakers of English and Spanish. In their study, participants were presented with visual frames of bug-like creatures half of which completed a novel manner-of-motion and the other half a path-of-motion movement. After viewing the frames, the participants were given a category-discrimination task and were asked to select one of four categories into which they best felt that each novel manner or path movement belonged. The results of the experiment revealed that monolingual English speakers focused more on manner of motion and monolingual Spanish speakers "performed significantly better on the path-discrimination task than on the manner-discrimination task, consistent with the relative prominence given to these two attributes in Spanish" (Kersten et al., 2010, p. 646). 
Results from the previous studies support the concept of a typologically-specific interpretation of motion events and the differences of such between $\mathrm{v}$ - and s-framed languages. Findings suggest that manner-of-motion distinctions are more apparent in $s$-framed languages (English) and that speakers of $\mathrm{s}$-framed languages attend more to the expression of manner than those of v-framed languages (Cadierno E Robinson, 2009; Cadierno \& Ruiz, 2006; Slobin, 1987). This notion posits great difficulty for the L2 learner as the motion-event expression inherent in their L1 may be well-established, thus hindering target-like L2 expression (Stam, 2006).

\section{Typology and language pedagogy}

While the need for more comprehensive pedagogy has been cited in much of the literature (Cadierno, 2008; Evans, 2013; Filipović, 2008; Gor, Cook, Malyushenkova, \& Vdovina, 2009; Spring, 2010; Wu, 2011), there is little clarity as to classroom-appropriate approaches to address the typology paradigm in L2 teaching and learning. Elliot and Yountchi (2009) addressed the pedagogical implications of Total Physical Response aimed at motion-event awareness, while others have suggested possible benefits of concepts such as negative evidence (Larrañaga, Treffers-Daller, Tidball, \& Gil Ortega, 2012; Strapp, Helmick, Tonkovic, \& Bleakney, 2011), as well as the Conceptual Approach (White, 2012) which applies aspects of cognitive linguistics to incorporate conceptualization and visualization into language pedagogy.

Elliot and Yountchi (2009) demonstrated the benefit of a pedagogical implementation aimed at fostering the acquisition of Russian verbs of motion through Total Physical Response (TPR) activities. In their TPR implementation, students at the novicehigh/intermediate-low levels were provided with randomly selected Russian sentences containing motion events and asked to act out the event portrayed in their sentence. As Russian verbs of motion contain multiple aspects of motion, students were required to distinguish between unidirectional and multidirectional movement (going one way or a round trip), as well as the mode of transportation ('by wheels' or 'by foot') which are conflated within the verb. A control group of students was also included which received traditional instruction of Russian verbs of motion. Both groups received explicit motion-event instruction, one via traditional grammar and translation instruction, and the other through Total Physical Response incorporating physical movement and language teaching. Both groups were subsequently tested to assess motionevent awareness post-intervention via a written exam that included a short conversation in Russian followed by multiple choice questions containing both multidirectional and unidirectional verbs of motion. Students were asked to choose the response that best represented the context of the conversation. Although somewhat restricted by a small participant sample, the researchers achieved mixed results indicating that the TPR group slightly outperformed the control group in only one of two post-implementation measures exceeding the control group in $45 \%$ of the responses. While the authors suggest the possible benefit of motionevent instruction to L2 learners, such confounding results certainly indicate the need for further investigation into language pedagogy aimed at motion-event awareness.

Negative evidence. The definition of negative evidence as utilized in this study agrees with that of Whang (2011) as "explanations about what is not correct in the target language, in addition to explanations of the rules of language" (p. 97), and, accordingly, includes overt statements as to the ungrammaticality of certain forms in English. Such a concept has been investigated in L2 pedagogy showing positive results in learner performance (Izumi \& Lakshmanan, 1998; Strapp, Helmik, Tonkovich, \& Bleakney, 2011). The learnability of the English passive by L1 Japanese learners was explored in Izumi and Lakshmanan (1998) who provided explicit instruction as to the impossibility of certain English passive constructions. The authors exposed students to the similarities and differences between English and Japanese passives, including examples of ungrammatical sentences in English. The participants provided opinions of each incorrect sentence, and the researchers gave explicit feedback as to the ungrammaticality of each construction. The participants also learned of the possible pragmatic failure that may occur from the incorrect use of such expressions in English. Finally, 
grammaticality judgment post-test results were compared with baseline scores demonstrating that the use of negative evidence proved highly effective as a method of teaching English passives with the mean error score of the experiment group dropping from $43.8 \%$ to $0.0 \%$. The authors conclude that "further research on the role of negative evidence in SLA is certainly worthwhile and can offer useful insights to both researchers and teachers" (Izumi $\mathcal{E}$ Lakshmanan, 1998, p. 99).

Negative evidence was also tested relating to L1 word learning in Strapp, Helmik, Tonkovich, and Bleakney (2011) who anticipated that adults would benefit more from negative rather than positive evidence when learning invented vocabulary. Participants were provided with novel nouns and verbs in storybook form and asked to produce noun and verb forms independently. The researchers exposed all participants to negative evidence of only two novel nouns and verbs and positive evidence of the remaining vocabulary. Finally, the participants were tested and a significant main effect $(F(2,89)=$ $126.52, p=.01, \mathrm{\eta} 2=.62$ ) was reported for an oral production task containing nouns and verbs taught via negative evidence when compared with positive evidence. While the study focused specifically on L1 word learning, the authors offer pedagogical implications for L2 learning and suggest that use of negative evidence may serve to eliminate errors related to generalizations and may also foster target-like grammar (Strapp, Helmik, Tonkovich, $\mathcal{E}$ Bleakney, 2011).

The Conceptual Approach. The Conceptual Approach, as proposed by White (2012), incorporates aspects of the cognitive linguistic framework to address phrasal verb instruction to non-native speakers of English. Although phrasal verbs differ slightly in form and use, the conceptualization and visualization of the motion, manner, and path constructions investigated in this study, as espoused in the Conceptual Approach, may also prove beneficial as both forms share the verb and preposition (satellite) collocations that so frequently confound L2 learners of English. White (2012), in the first step of his instructional design, incorporated a new orientation to phrasal verbs (p. 422) in which the physical and spatial characteristics of verb and particle combinations are situated in "a place relative to the zone of activity" (p. 423). In this sense, verb and particle collocations were evaluated and spatial relationships between physical surroundings, the speaker's mind, or any other metaphorical spatial relationship were scrutinized. To further illustrate the zone of activity, White (2012) provides the examples of "Throw out the trash" and "Welcome to the meeting. Please throw out any ideas you might have" (p. 423). These two examples which both employ the phrasal verb to throw out each demonstrate a slightly different zone of activity. The first represents the physical space surrounding the speaker, while the latter represents an idea contained within the speaker's mind.

In the following steps, White had students collect phrasal verb examples in context, explore the meanings of the collected phrases, convey the meaning of such novel expressions graphically, and finally share their interpretations with fellow students. Particular attention was paid to the zone of activity as depicted in each of the students' drawings so that students could visualize inherent spatial relationships. White notes that the Conceptual Approach is not an absolute approach to the teaching of phrasal verbs; however, modest pre- and post-test results were reported after implementation. The average number of accurate responses on the 13 item post-test increased from 4.07 to 4.67 ( $z=-2.45$, $p<.05, r=-.61)$. White's position does agree, however, with Wu (2011) who suggests that "the use of pedagogical tasks promoting functional use of spatial expressions in context would be desirable as they would provide L2 learners with embodied experience that may facilitate development of the L2 form-meaning mappings" (p. 444). Furthermore, White (2012) makes the poignant suggestion that the Conceptual Approach is not restricted to phrasal verb instruction and may benefit students on a broad range of L2 subject matter.

\section{The present study}

The difficulty for mastery of target-like lexicalizations of English manner-of-motion verbs (Aske, 1989; Filipović, 2008; Gor, Cook, Malyushenkova, \& Vdovina, 2009; Stam, 2006; 
2010), paired with the apparent lack of pedagogical materials aimed at developing knowledge within this area (Tyler $\varepsilon$ Evans, 2004) inspired the instructional design of this pedagogicalintervention. In accordance with the goal of developing s-framed motion-event awareness as well as fostering target-like expression of manner of motion, the present investigation addressed the following research questions:

- Can a pedagogical intervention focusing on negative evidence (Izumi \& Lakshmanan, 1998; Strapp, Helmik, Tonkovich, \& Bleakney, 2011) and explicit rule explanation (Gor, \& Cook, 2010), paired with aspects of the Conceptual Approach (White, 2012), promote the targetlike use of verbs of motion in L1 Spanish ELLs?

- Will increasing students' repertoire of manner-ofmotion verbs equate to more pervasive and targetlike use in post-intervention writing samples?

- How will the direct instruction of typology influence ELL motion-event expression in regards to path-of-motion and manner-ofmotion verbs?

Based on the typological differences between English and Spanish and the lack of explicit exposure to these structures in EFL teaching material, it was hypothesized that (1) a high correlation of path verbs as a function of total motion verbs would be prevalent in pre-intervention writing samples as this is characteristic of the Spanish L1. Additionally, it was hypothesized that (2) native-like manner-of-motion expressions with appropriate use of path satellites would be infrequent in pre-intervention writing samples. Finally, with a developed understanding of manner-of-motion verbs in English, it was hypothesized that (3) post-intervention writing samples would (a) express more manner of motion due to increased vocabulary and awareness and that (b) a greater percentage of such expressions would achieve target-like proficiency.

\section{Methodology}

Participants. The participants in the present study were native Spanish-speaking students at a private university in Bogotá $(N=14)$ who were enrolled in a B1 level class as per the Common
European Framework (Council of Europe, 2011). The participants were all enrolled in an English course at the time of the investigation, although program majors varied within the group. Participant age ranged from 19 to $30(M=23.9, S D=3.2)$, and the participants reported a wide range of previous time studying English (from just eight weeks to three years) with a mean of 1.16 years $(S D=$ 1.53). All data were collected anonymously, and the participants were each assigned a random number to be used to identify their pre- and post-intervention writing samples without revealing identity. The participants were also informed that their writing samples were to be collected for research purposes and that their performance would not affect their overall class grade.

Procedure. In order to address the research questions proposed, a nine-hour pedagogical intervention was designed and implemented with the participants over a two week period. Classes met three days a week for three hours per session with approximately 1.5 hours of instruction dedicated to motion-event expression. The concepts of explicit instruction and explanation (Gor \& Cook, 2010), negative evidence (Izumi \& Lakshmanan, 1998; Strapp, Helmik, Tonkovich, \& Bleakney, 2011), and specific aspects of the Conceptual Approach (White, 2012) were incorporated into the instructional design. Prior to the start of the intervention, the instructor informed the students that they would be engaged in activities designed to increase their awareness of English motion-event expression.

The first phase of the implementation involved the explicit instruction of typology and a comparison between v- and s-framed languages (Spanish and English respectively). The instructor introduced students to the concept of typology in the first session and explicitly taught the terms motion, figure, ground, path, and manner, the main components of motion-event expression which were relevant to the study (Talmy, 2000). The concept of v- and s-framed languages was also exemplified in the first session, and the participants were presented with comparisons to view the categorical differences between the two typologies. Specific differences between motion event expression in English and Spanish were then elucidated, and the participants were provided 
with copious examples of expressions of motion in both languages (Spring, 2010). The first session concluded with visualizations of motion events followed by target-like expressions in both languages. Images were projected which depicted motion events, particularly those containing telic movement. After viewing characteristic target-like expressions in English, the participants translated the events into Spanish (Camacho, 2010). The instructor directed students' attention to events which embodied aspects of telicity, particularly with the English satellites out of, into, across, and through.

In the next session, the participants were engaged in a thorough demonstration of the use of English prepositions as path satellites, and prepositions were visualized using animations reproduced via a projector. Contrastive examples were provided such as the man jumped over the puddle as opposed to the man jumped into the puddle, and these were visualized as well using projected slides containing photographs of the described movements. Once sufficient examples were given, the instructor provided students with target-like expressions in English, and they were asked to create a graphic depiction of such events on paper, consistent with that advocated in the Conceptual Approach (White, 2012). Examples such as the man ran across the road and the cat jumped over the box were used. Students also discussed the meaning of prepositions and their function of conveying spatial relationships. Special focus was made on verb/path collocations which conveyed telicity (e.g. flying out of, crawling under, and falling into). The instructor presented visual (wordless) representations of these collocations in the form of drawings to the participants who then attempted to construct target-like expressions to describe the pictured motion events.

Following the session focused on path satellites, the participants received explicit instruction in the use of English manner-of-motion verbs. This lesson served the dual purpose of exposing students to target-like evidence of manner/path combinations, as well as to extend their range of manner verbs (Gor $\&$ Cook, 2010). 14 specific manner-of-motion verbs were selected and taught in this session so that students would have resources beyond the basic swim, jump, and run which dominated pre- intervention writing samples (please see Appendix A for a list of manner-of-motion verbs taught in this lesson). Once the manner-of-motion verbs had been taught, the participants were provided with negative evidence (Larrañaga, Treffers-Daller, Tidball, $\varepsilon$ Gil Ortega, 2012; Strapp, Helmick, Tonkovich, $\mathcal{E}$ Bleakney, 2011) for the first time. Examples of negative evidence included the children crossed the lake swimming and the boy passes over the cat jumping. The instructor directed student attention to such negative examples and explained that although perhaps grammatically correct, the provided lexicalizations were not representative of the English language. Finally, the participants utilized their newlyacquired knowledge to correct the negative examples.

The final sessions of the implementation were dedicated to further examination of the participants' narratives which had been constructed at the outset of the study. The participants were asked to identify motion events within their writing, to categorize such expressions based on the use of neutral motion, path, or manner-of-motion verbs, and to attempt to incorporate their knowledge of s-framed typology into their writing. The participants were given opportunities to consult with their peers and offer feedback on their writing, thus making suggestions as to where motion event expression may not achieve target-like proficiency.

Supplemental material incorporated into the lessons included short narratives which provided ample exposure to motion events, as well as cloze activities in which the participants were asked to select appropriate manner-of-motion verbs and path satellites to complete a story. As a further step to promote a conceptual understanding of the function of manner-of-motion verbs and path satellites, the participants were given out-of-class assignments in which they constructed visual representations of the motion events contained within their original narratives and, subsequently, shared such visuals with the class (White, 2012, p. 425). Consistent with the ideas proposed in the Conceptual Approach (White, 2012), this activity was carried out later in the implementation as it may be advantageous that "before asking the class to draw pictures, teachers... spend time on the conceptualization of particles and prepositions" (p. 430). 


\section{Data analysis}

Pre- and post-intervention writing samples were collected and analyzed to measure the use of English verbs of motion (VoM). Students were asked to write a brief narrative depicting an escape in which they were to include approximately ten movements or actions taken by characters in the story. The first narrative was completed before instruction began, and the final narrative was written once the instruction had concluded. To begin, all verbs and verbal phrases were extracted from the narratives and analyzed based on the categories that follow. In accordance with $\mathrm{Ji}$, Hendriks, and Hickman (2011), verbal expressions which did not denote motion were excluded from the analysis as such expressions fell outside of the interest of the present study. Non-motion verbs (e.g. have, see, take), copulae (e.g. be, become, seem), as well as motion verbs expressing reslutative (caused) motion and not transitory motion (e.g. open, close, etc.) were consequently disregarded. The remaining motion verbs were classified via the following categories: Total motion verbs (TM), path verbs $(\mathrm{P})$, neutral-motion verbs (NM), manner-of-motion verbs $(M M)$, and finally, target-like motion/satellite collocations (T-MS). Neutral-motion verbs (NM) are those verbs which inherently communicate motion, but fail to communicate either path or manner of motion (e.g. to come and to go). Appendix B provides examples of each category of verbs present in student writing samples. Table 1 illustrates preand post-intervention VoM data.

Table 1. Mean Pre-and Post-intervention Verb Usage (SD in parenthesis)

\begin{tabular}{cccccc}
\hline & TM & P & NM & MM & T-MS \\
\hline Pre-intervention & $6.21(2.64)^{* * *}$ & $.57(1.16)$ & $1.64(1.45)^{* * *}$ & $3.86(1.41)^{* * *}$ & $.93(.92)^{* * * *}$ \\
Post-intervention & $7.79(2.75)^{* * *}$ & $.64(1.01)$ & $1.21(1.42)^{* * *}$ & $5.93(2.3)^{* * *}$ & $4.21(1.81)^{* * *}$ \\
\hline
\end{tabular}

Note. $\mathrm{N}=14 ; * * \mathrm{p}<.01 * * * \mathrm{p}<.001$

\section{Target-like Motion/satellite Collocations}

Target-like motion/satellite collocations (T-MS) were included so that effective attempts to collocate path via a satellite could be recorded and analyzed pre- and post-intervention. Such a category was necessary to address the hypotheses that nativelike manner-of-motion expressions with appropriate use of path satellites would be infrequent in preintervention writing samples, and that a greater percentage of post-intervention expressions would achieve target-like proficiency.

In order to ensure judgment reliability of targetlike motion/satellite collocations, such expressions were evaluated using the Corpus of Contemporary American English (Davies, 2008), thus diminishing rater subjectivity. The COCA corpus is comprised of approximately 450 million words which include entries from scientific journals, spoken text, magazines, newspapers, etc. Collocation searches using raw frequency data were conducted and a threshold type frequency of two (2) tokens was selected as the minimum for consideration as target-like collocations. Partial and full-phrase searches were completed and included morphologically-inflected forms (denoted below with $*$ ) which were considered as acceptable uses of such expressions. Furthermore, parts-ofspeech tags were included to broaden searches which included singular common nouns (denoted below as [NN1]) to guarantee that such parts of speech indeed function in such positions. This idea is illustrated in examples (1a), (1b), and (1c):

(1a) Student T-MS expression: "came back to jail"

(1b) Partial search: "c*me back" $(40,496$ token frequency)

(1c) Full search: "c*me back to [NN1]" (350 token frequency) 
In the example (1b), "c*me back" would permit the corpus to return results of both past and presenttense conjugations of the verb to come distinguished by the (a) and (o) simulfixes. As come back and came back are equally plausible in English, the total token frequency was considered for these expressions. The initial, partial search for the expression (1b) returned a token frequency of 40,496 , with a full search (1c) including the singular common noun tag [NN1] returning a token frequency of 350, thus allowing the researcher to confirm that such an expression was target like. Collocations such as jump to tree ( 0 ) and run behind of him (0) returned a token frequency of zero (0) and, therefore, were determined to be non-target like in their use.

Pre-intervention writing samples demonstrated 36 attempted motion and path satellite collocations (41.4\% of total motion verbs); however, corpus evaluation revealed that of the 36 attempts, only 15 tokens reached target-like proficiency (41.7\% of attempts, $M=.93, S D=.92, \mathrm{p}<.01$ ), which comprised only a small percentage of total motion verbs (17.2\%). Furthermore, of the 15 T-MS, $86.7 \%$ were motion/satellite collocations which employed neutral-motion verbs; therefore suggesting that students approximating the B1 level prefer the verbs to come and to go over motion verbs which also express manner. These data confirm the second hypothesis that target-like manner of motion and path satellite collocations would be infrequent in student writing samples prior to explicit instruction in typology. As these expressions are rare in the students' L1 (Spanish), it is conceivable that limited exposure to such structures in English have hindered awareness in this area.

Post-intervention writing samples revealed a significant improvement with regard to T-MS expressions. An increase in total number of motion and path satellite collocations was observed (70) with 59 achieving target-like proficiency $(84.3 \%, M$ $=4.21, S D=1.81, \mathrm{p}<.01)$. A paired-samples $t$-test was conducted to evaluate the significance of preand post-test T-MS performance. Results (at $\alpha=.05$ ) indicated that post-intervention T-MS expressions $(M=4.21, S D=1.81)$ demonstrated significant improvement over pre-intervention samples ( $M$ $=.93, S D=.92)$, with $t(13)=6.34, \mathrm{p}<.001$,
Cohen's $d=1.7$. The $95 \%$ confidence interval for the mean difference was 2.17 to 4.41 . $T$-test results confirm the third hypothesis that instruction would increase overall use of manner-of-motion verbs, with a greater percentage of such achieving targetlike proficiency.

\section{Neutral-motion Verbs}

Neutral-motion verb use remained relatively constant with an insignificant mean difference of -.43 pre- and post-intervention; $t(13)=1.15, \mathrm{p}>$ .05 , Cohen's $d=.31$. Throughout the pedagogical implementation, students learned that the neutralmotion verbs to come, to go, and even to get with a satellite function in the same way as manner-ofmotion verbs in that they often receive a satellite collocation to express path of motion. While the quantity of neutral-motion verbs remained constant, the target-like use of such verbs with path satellite collocations was evidenced in post-intervention data (14 NM with satellite attempts, $78.6 \%$ accuracy). Expressions such as came out of her house, and it will be very easy to get there demonstrate that students began using neutral-motion verb/satellite collocations in a target-like manner. These and similar expressions are particularly common in English; thus, increased proficiency in this area must certainly be regarded as a positive aspect.

\section{Path Verbs}

With a low mean frequency for pre-intervention path verbs $(M=.57, S D=1.16)$, a Pearson's product-moment correlation was conducted to assess the relationship between the total motion verbs and path verbs. An insignificant correlation between the two variables was reported $(r=.46, d f$ $=12, \mathrm{p}>.05)$; thus, the first hypothesis postulating a significant correlation between total motion and path-of-motion verbs in pre-intervention writing was rejected. Although Spanish typically confers greater focus on path of motion, the data demonstrate that ELLs approaching the B1 level did not follow native-like tendencies for path verbs as is pervasive in their L1 (see Larrañaga, Treffers-Daller, Tidball, E Gil Ortega, 2012; and Filipović, 2008, for a description of Spanish manner verb frequency). This may be attributed to the fact that, at this level, 
students have sufficient working knowledge of English motion-event expression to avoid path verb usage. It is equally plausible that even their limited access to native input has provided them with enough evidence that such verbs are infrequent in common language.

\section{Discussion}

As predicted, the data serve to confirm the hypothesis that infrequent use of mannerof-motion/path satellite collocations would be present in student writing pre-intervention, and that students would attempt more manner verb usage with greater accuracy after being exposed to explicit instruction in the typology of English motion events. T-MS pre-intervention results suggest that low-intermediate students may be more familiar with the use of neutral-motion verbs (to come and to go) as these are quite pervasive both in speech as well as in instructional material. Both of these verbs are commonly taught at the elementary and intermediate levels and, thus, may be more readily understood by learners. While neutral-motion verb use was prevalent in pre-intervention writing, the data also suggest that low-intermediate students who are explicitly exposed to manner-of-motion verbs may be more inclined to attempt such collocations. Additionally, the attempted manner and path satellite collocations may also more closely approximate target-like speech following the pedagogical intervention. This may be attributed to the fact that these students have been directly involved in learning opportunities which expose the lexicalization patterns of manner-of-motion verbs in English, as well as the explicit instruction of English manner-of-motion verbs.

In answering the research questions, the data demonstrate that pedagogical implementations specifically designed to promote motion-event awareness may have a positive effect on the desired outcomes of increasing target-like manner-ofmotion verb and satellite use. Additionally, an increased repertoire of manner-of-motion verbs seems to equate to more pervasive use of such verbs when expressing motion events in English as more students attempted to use a wider variety of manner verbs in post-intervention writing samples. Thus, incorporating typology-specific classroom activities including explicit instruction, negative evidence, and conceptualization may be a significant first step in increasing student proficiency within this area. Overall, results from the present study begin to paint a picture of the role of explicit instruction of the unique typological characteristics of English in the second language classroom.

\section{Limitations and conclusions}

Following a pre-experimental pretest-posttest design (Larsen-Freeman \& Long, 1991), the present study lacks possible statistical analysis against the outcomes of a control group. Furthermore, the participants involved in this study represent a convenience sample as they had previously enrolled in an EFL course taught by the author at their university. As such, generalizations to a larger population cannot be inferred; however, there is no reason to believe that the participants in this study would perform differently than those from a random sample of a similar population. Furthermore, only students at the low-intermediate level were included, thus warranting further investigation designed to evaluate such results between proficiency levels. As the present study incorporated an intervention which included various pedagogical approaches (explicit instruction, negative evidence, and the Conceptual Approach), it may be favorable to separate these features and address the effects of such individually among equal groups of language learners. This would provide insight into the benefit that each aspect may offer to L2 learners independent of the others. Finally, it is difficult to make assumptions as to the retention rate for satellite-framed motion event expression as participants were tested directly at the conclusion of instruction and not again after any significant time had elapsed. Nevertheless, the potential of including language pedagogy related to the typology of motion-event expression is certainly recognizable from the results gleaned from this study. 


\section{References}

Aske, J. (1989). Path predicates in English and Spanish: A closer look. Proceedings of the Fifteenth Annual Meeting of the Berkeley Linguistics Society. Berkeley: Berkeley Linguistics Society, 1-14.

Brown, A., \& Chen, J. (2013). Construal of manner in speech and gesture in Mandarin, English, and Japanese. Cognitive Linguistics, 24(4), 605-631.

Cadierno, T. (2008). Motion events in Danish and Spanish: A focus on form pedagogical approach. In S. De Knop \& T. De Rycker (Eds.). Cognitive approaches to pedagogical grammar (pp. 259-294). Berlin/New York: Mouton de Gruyter.

Cadierno, T. (2010). Motion in Danish as a second language: Does the learner's L1 make a difference? In Z-H. Han \& T. Cadierno (Eds.). Linguistic relativity in second language acquisition: Thinking for speaking (pp. 1-33). Clevedon: Multilingual Matters.

Cadierno, T., \& Robinson, P. (2009). Language typology, task complexity and the development of L2 lexicalization patterns for describing motion events. Annual Review of Cognitive Linguistics, 7(1), 245-276.

Cadierno, T., \& Ruiz, L. (2006). Motion events in Spanish L2 acquisition. Annual Review of Cognitive Linguistics, 4(1), 183-216.

Camacho, J. (2010). Classroom research on the teaching of phrasal verb combinations. Quaderns Digitals, 64. Retrieved from the Quaderns Digitals database.

Carroll, M., Murcia-Serra, J., \& Watorek, M. (2000). The relevance of information organization to second language acquisition studies. Studies in Second Language Acquisition, 22(3), 441-466. doi:10.1017/ S0272263100003065

Cifuentes-Férez, P., \& Gentner, D. (2006). Naming motion events in English and Spanish. Cognitive Linguistics, 17(4), 443-462.

Council of Europe (2011). Common European Framework of Reference for: Learning, Teaching, Assessment. Council of Europe.

Davies, M. (2008). The Corpus of Contemporary American English: 450 million words, 1990-present. Available online at http://corpus.byu.edu/coca/.

Elliott, E., \& Yountchi, L. (2009). Total physical response and Russian multi- and unidirectional verbs of motion: A case study in acquisition. Slavic $\mathcal{E}$ East European Journal, 53(3), 428-450.

Evans, R. (2013). Linguistic typology and verb structure: A comparative approach for the EFL classroom. In W. Escobar (Ed.) Social research applied to English language teaching: Theory and methods (pp. 2136). Bogotá: Editorial Universidad El Bosque.

Evans, V., E Green, M. (2006). Cognitive linguistics: An introduction. Edinburgh: Edinburgh University Press.

Filipović, L. (2008). Typology in action: Applying typological insights in the study of translation. International Journal of Applied Linguistics, 18(1), 23-40.

Filipović, L., E Vidaković, I. (2010). Typology in the L2 classroom: Second language acquisition from a typological perspective. In M. Pütz, L. Sicola (Eds.), Cognitive processing in second language acquisition: Inside the learner's mind (pp. 269-291). Amsterdam Netherlands: John Benjamins Publishing Company.

Gor, K., E Cook, S. (2010). Nonnative processing of verbal morphology: In search of regularity. Language Learning, 60(1), 88-126.

Gor, K., Cook, S., Malyushenkova, V., \& Vdovina, T. (2009). Verbs of motion in highly proficient learners and heritage speakers of Russian. Slavic $\mathcal{E}$ East European Journal, 53(3), 386-408.

Hacohen, A. (2006). The psychological reality of the telic/ atelic distinction: Evidence from adult and child Hebrew. Proceedings of the 21st Annual Meeting of the Israel Associations for Theoretical Linguistics, (unnumbered).

Hasko, V. (2009). The locus of difficulties in the acquisition of Russian verbs of motion by highly proficient learners. Slavic \& East European Journal, 53(3), 360-385.

Ibarretxe-Antuñano, I. (2004). Language typologies in our language use: The case of Basque motion events in adult oral narratives. Cognitive Linguistics, 15(3), 317-349.

Ibarretxe-Antuñano, I. (2009). Path salience in motion events. In J. Guo, E. Lieven, N. Budwig, S. Ervin-Tripp, K. Nakamura, Ş. Õzçalişkan (Eds.), Crosslinguistic Approaches to the psychology of language: Research in the tradition of Dan Isaac Slobin (pp. 403-414). New York, NY US: Psychology Press.

Ibarretxe-Antuaño, I. (2012). Linguistic typology in motion events: Path and manner. In: Anuario del Seminario de Filología Vasca 'Julio de Urquijo'. International Journal of Basque Linguistics and Philology.

Izumi, S., E Lakshmanan, U. (1998). Learnability, negative evidence and the L2 acquisition of the English passive. Second Language Research, 14(1), 62-101.

Ji, Y., Hendriks, H., \& Hickmann, M. (2011). How children express caused motion events in Chinese and English: Universal and language-specific influences. Lingua, (12), 1796-1819. doi:10.1016/j.lingua.2011.07.001 
Kersten, A. W., Meissner, C. A., Lechuga, J., Schwartz, B. L., Albrechtsen, J. S., \& Iglesias, A. (2010). English speakers attend more strongly than Spanish speakers to manner of motion when classifying novel objects and events. Journal of Experimental Psychology: General, 139(4), 638-653. doi:10.1037/a0020507

Larrañaga, P., Treffers-Daller, J., Tidball, F. \& Gil Ortega, M. (2012). L1 transfer in the acquisition of manner and path in Spanish by native speakers of English. International Journal of Bilingualism, 16(1), 117-138.

Larsen-Freeman, D., \& Long, M.H. (1991). An introduction to second language acquisition research. New York: Longman.

Naigles, L. R., \& Terrazas, P. (1998). Motion-verb generalizations in English and Spanish: Influences of language and syntax. Psychological Science, 9(5), 363-369.

Papafragou, A., \& Selimis, S. (2010). Lexical and structural biases in the acquisition of motion verbs. Language Learning and Development, 6, 87-115.

Papafragou, A., Massey, C., \& Gleitman, L. (2006). When English proposes what Greek presupposes: The cross-linguistic encoding of motion events. Cognition, 98, B75-87.

Rau, D., Chun-Chieh, W., \& Hui-Huan Ann, C. (2012). Investigating motion events in Austronesian languages. Oceanic Linguistics, 51(1), 1-17.

Skordos, D., \& Papafragou, A. (2014). Lexical, syntactic, and semantic-geometric factors in the acquisition of motion predicates. Developmental Psychology, 50 (7), 1985-1988.

Slobin, D. I. (1987). Thinking for speaking. Proceedings of the thirteenth annual meeting of the Berkeley Linguistics Society, 435-445.

Spring, R. (2010). A look into the acquisition of English motion event conflation by native speakers of
Chinese and Japanese. Proceedings of the 24th Pacific Asia Conference on Language, Information and Computation, 563-572.

Stam, G. (2006). Thinking for speaking about motion: L1 and L2 speech and gesture. IRAL: International Review of Applied Linguistics in Language Teaching, 44(2), 145-171. doi:10.1515/IRAL.2006.006

Stam, G. (2010). Can an L2 speaker's patterns of thinking for speaking change? In Z-H. Han $\mathcal{E}$ T. Cadierno (Eds.). Linguistic relativity in second language acquisition: Thinking for speaking (pp. 59-83). Clevedon: Multilingual Matters.

Strapp, C. M., Helmick, A. L., Tonkovich, H. M., Bleakney, D. M. (2011). Effects of negative and positive evidence on adult word learning. Language Learning, 61(2), 506-532.

Talmy, L. (2000). Toward a cognitive semantics, vol. II: Typology and process in concept structuring. Cambridge, MA US: The MIT Press.

Tyler, A., E Evans, V. (2004). Applying cognitive linguistics to pedagogical grammar: The case of over. In $M$. Achard, S. Niemeier (Eds.), Cognitive linguistics, second language acquisition, and foreign language teaching (pp. 257-280). Berlin, Germany: Mouton de Gruyter.

Whang, M. (2011). Language teaching: Linguistic theory in practice. Edinburgh: Edinburgh University Press.

White, B. J. (2012). A conceptual approach to the instruction of phrasal verbs. Modern Language Journal, 96(3), 419-438.

Wu, S. (2011). Learning to express motion events in an L2: The case of Chinese directional complements. Language Learning, 61(2), 414-454. doi:10.1111/ j.1467-9922.2010.00614.x 


\section{Appendix A}

Manner-of-motion Verbs Taught During Instruction

To crawl

To race

To swing

To bounce

To roll

To drop

To slide

To leap
To stumble

To trip

To tiptoe

To flee

To escape

To creep

To sneak

To scramble

\section{Appendix B}

Verb Categorizations and Examples for Pre- and Post-test Analysis

- (P) Path Verbs:

To go, to come, to arrive, to leave, to move, to enter

- (NM) Neutral-motion Verbs:

To go, to come

- (MM) Manner-of-motion Verbs:

To run, to jump, to drive, to escape, to swim, to climb, to walk, to cross, to sneak, to tip toe, to leap, to rush, to crawl, to trip, to race
- (T-MS) Target-like Motion/satellite Collocations (in post-test samples):

Get out of jail, come in the room, run on the stairs, go to the door, run for the jungle, walk around the river, slide into the tree, leap over the rabbit, creep between the bushes, crossed the yard, climb through a tube, jump over the barrier, flee into the plants, run down the mountain, sneak through the broken window, tip toe behind the mayor's office, swim across the river, etc. 